\title{
Perilaku Kepemimpinan Lintas Budaya Dimensi LDBQ XII Pada Kepuasan Kerja Praktisi Perbankan Di Jawa Tengah
}

\author{
Asri Laksmi Riani ${ }^{1}$, Dodi Wirawan Irawanto², Yanki Hartijasti ${ }^{3}$, Ulfa Puspita ${ }^{4}$ \\ Universitas Sebelas Maret Indonesia ${ }^{1,4}$, Universitas Brawijaya Indonesia ${ }^{2}$, Universitas \\ Indonesia ${ }^{3}$ \\ asrilaksmi_fe@staff.uns.ac.id
}

\section{Article History}

received $1 / 9 / 2021$

revised 1/10/2021

accepted 1/11/2021

\begin{abstract}
This study identifies the determinants of leadership behavior using LBDQ XII and job satisfaction with a sample of bank staff and managers in the island of Central Java. The leadership style in a country is characterized by cross-cultural as a form of national culture that plays an important role in the application of the leadership theory in a country. The role of leadership on the job satisfaction of supervisors and managers is very important to know to see their performance, which will result in organizational performance. The data collection in this study was conducted by distributing online questionnaires to 60 entrepreneurs in the banking sector. LBDQ XII containing 100 instruments and job satisfaction using the Minnesota Satisfaction Questionnaire (MSQ) containing 20 items in the study population. The results show that Indonesian banking practitioners, especially in Central Java, have leaders who are persuasive, production emphasis, predictive accuracy, tolerance for freedom and initiative for structure have the most role in the job satisfaction of banking supervisors and managers in Central Java, respectively Java.
\end{abstract}

Keywords: $L B D Q X I I$ leadership, Job satisfaction

\begin{abstract}
Abstrak
Penelitian ini mengidentifikasi determinan perilaku kepemimpinan menggunakan LBDQ XII dan kepuasan kerja dengan sampel staf dan manajer perbankan di pulau Jawa Tengah. Gaya kepemimpinan disuatu negara ditandai dengan lintas budaya sebagai bentuk budaya nasional yang berperan penting dalam penerapan teori kepemimpinan disuatu Negara. Peran kepemimpinan terhadap kepuasan kerja supervisor dan manajer sangat penting untuk diketahui agar dapat dilihat kinerja mereka yang akan menghasilkan kinerja organisasi. Pengumpulan data dalam penelitian ini dilakukan dengan menyebarkan kuesioner secara online kepada 60 praktisi bisnis di sektor perbankan. LBDQ XII yang berisi 100 instrumen dan kepuasan kerja dengan menggunakan Minnesota Satisfaction Questionnaire (MSQ) yang berisi 20 item pada populasi penelitian. Hasil penelitian menunjukkan bahwa praktisi Perbankan Indonesia khususnya di Jawa Tengah memiliki pemimpin yang persuasiveness, production emphazicess, predictive accuracy, tolerance of freedom dan initiation for structure secara berturut-turut paling berperan pada kepuasan kerja karyawan supervisor dan manajer perbankan di Jawa Tengah.

Kata kunci: Kepemimpinan LBDQ XII, Kepuasan kerja
\end{abstract}

Social, Humanities, and Education Studies (SHEs): Conference Series https://jurnal.uns.ac.id/shes

p-ISSN 2620-9284

e-ISSN 2620-9292 


\section{PENDAHULUAN}

Perbankan merupakan industri keuangan yang berfungsi sebagai perantara keuangan (financial intermediary), baik antar masyarakat maupun antar negara. Perbankan memiliki fungsi yang sangat penting bagi perekonomian suatu bangsa. Pentingnya peran bank mengakibatkan pemerintah yang bekerjasama dengan pimpinan perbankan menjaga stabilitas industri keuangan. Selain itu bank merupakan badan usaha yang memiliki peran dalam menghimpun dana dan menyalurkan kembali kepada masyarakat (Undang-undang Nomor 10 Tahun 1998). Fungsi utama dari bank yaitu menyediakan jasa yang menyangkut penyimpanan nilai dan perluasan kredit. Peran pemimpin sangat penting dalam menjaga keberlangsungan suatu organisasi. Peran pemimpin di organisasi perbankan menjadi sangat penting di dalam menggerakkan organisasi sesuai dengan tujuannya. Posisi pimpinan menjadi sangat krusial dan diharapkan mempunyai peranan dalam meningkatkan serta menjaga keseimbangan dalam organisasi. Tanpa adanya pemimpin maka setiap masalah yang timbul di dalam organisasi akan sangat sulit untuk diselesaikan, sehingga dibutuhkan seorang pemimpin yang cepat dan cermat dalam mengambil keputusan dalam mencapai tujuan organisasi.

Ketika seorang pemimpin mentransfer emosi dan pikirannya kepada karyawan dengan cara yang kuat, akan mempengaruhi emosi karyawan, kinerja dan kepuasan kerja karyawan (Goleman, 2002). Ini karena pemimpin memiliki efek tidak hanya pada emosi dan pikiran karyawan tetapi juga pada motivasi-nilai, kebutuhan, tuntutan, dan keinginan-harapan mereka, yang berperan penting dalam tindakan mereka menuju tujuan yang diidentifikasi (Burns, 2007). Sebuah tinjauan literatur menunjukkan terdapat hubungan antara kepuasan kerja dan gaya/pendekatan kepemimpinan, seperti kepemimpinan transformasional (Chen, 2005a, 2005b; Derzsy, 2003; Rothfelder, Ottenbacher, \& Harrington, 2013; Shibru \& Darshan, 2011; Walumbwa, 2002), kepemimpinan instruksional (Thompson, 2005; Westley, 2000); kepemimpinan etis (Einstein, 2013; Ruiz-Palomino, Sa'ez-Martı nez, \& Martı nez-Cañas, 2013), kepemimpinan otentik (Darvish \& Rezaei, 2011; Giallonardo, Wong, \& Iwasiw, 2010; Stearns, 2012), kepemimpinan karismatik (Holloway, 2012; Vlachos, Panagopoulos, \& Rapp, 2013), kepemimpinan yang melayani (Barnes, 2011; Caffey, 2012; Drury, 2004; Hebert, 2003; Miears, 2004; Wilson, 2013), kepemimpinan yang mendukung (Lowhorn, 2009; Tomsheck, 1985) dan partisipatif kepemimpinan (Gharibvand, 2012; Kim, 2002; Nongmak, 1986).Demikian pula hubungan antara kepuasan kerja denga perilaku kepemimpinan (Konto, 1986; Lin, 1998; Marra, 1978; Oberlin, 1980; Prest, 1993), praktik kepemimpinan (Bathini, 1996; Miller, 2003; Roelle, 2010; Taylor, 1996), keterampilan kepemimpinan (Abraham \& Grant, 2008; Ivie, 2007) dan efisiensi kepemimpinan (Henson, 1984; McElhaney, 2003; Schulman, 1989) diselidiki. Penelitian ini dilakukan untuk menguji pengaruh kepemimpinan terhadap kepuasan kerja.

\section{A. Kepemimpinan dimensi LDBQ XII}

\section{KAJIAN TEORI}

Kuesioner LBDQ-XII (Leader Behaviour Description Questionnaire XII) untuk mengetahui preferensi kepemimpinan di Indonesia. Kuesioner ini digunakan sebagai alat uji instrumen utama dengan pertimbangan sudah diakui dan banyak digunakan dalam literatur kepemimpinan dunia seperti yang dilakukan pada studi The Ohio State Theory of Leadership yang kemudian dioperasionalkan menjadi LBDQ-XII (info lebih lengkap dapat dilihat pada http://fisher.osu.edu/research/ldbq/) (Northouse, 2013). Selain itu, berdasarkan studi literatur diketahui bahwa instrumen LBDQ-XII menjadi satu-satunya kuesioner non- eksperimental yang valid dan reliabel dan dirancang untuk meneliti perilaku pemimpin yang diinginkan dengan menggunakan basis sampel di banyak budaya berbeda di seluruh dunia yang diterbitkan oleh tim yang kompeten 
(Litrell, 2018). Kuesioner ini dikembangkan dari The Ohie State Studies dengan meringkas item pertanyaan yang awalnya 1800 item menjadi 150 item pertanyaan (Hemphill \& Coons, 1957) yang kemudian dikurangi menjadi 100 pertanyaan (Stogdill, 1963). LBDQ-XII menjelaskan preferensi perilaku pemimpin yang disukai, menggunakan Skala Likert dengan 100 item pertanyaan. Dari 100 item ini, terdapat 12 faktor utama dimensi preferensi perilaku kepemimpinan.

Dua belas faktor utama dalam kuesioner LBDQ-XII yang digunakan sebagai berikut: Representasi (representation), Rekonsiliasi permintaan (demand reconciliation), Toleransi ketidakpastian (tolerance of uncertainty), persuasif (persuasiveness), inisiasi struktur (initiation of structure), toleransi kebebasan (tolerance of freedom), asumsi peran (role assumption), pertimbangan (consideration), penekanan produksi (production emphasis), akurasi prediktif (predictive accuracy), integrasi (integration), dan orientasi superior (superior orientation) (Stogdill, 1963).

Dua belas faktor LBDQ-XII menurutStogdill (1963), yaitu representation mengukur sejauh mana pemimpin memposisikan diri sebagai perwakilan kelompok. Demand reconciliation mencerminkan seberapa baik pemimpin dapat meredam berbagai tuntutan dan mengurangi kekacauan yang terjadi. Tolerance of uncertainty menggambarkan sejauh mana pemimpin mampu mentolerir ketidakpastian. Persuasiveness mengukur sejauh mana pemimpin menggunakan persuasi dan argumen secara efektif untuk menunjukkan keyakinan yang kuat. Initiation of structure mengukur sejauh mana pemimpin secara jelas mendefinisikan peran mereka sendiri dan membiarkan pengikut mengetahui apa yang diharapkannya. Tolerance of freedom mencerminkan sejauh mana pemimpin memungkinkan ruang lingkup bagi bawahan untuk mengambil inisiatif, keputusan, dan tindakan. Role assumption mengukur sejauh mana pemimpin menjalankan peran kepemimpinan secara aktif dibandingkan menyerahkan kepemimpinan kepada orang lain. Consideration menggambarkan sejauh mana pemimpin menghargai kenyamanan, kesejahteraan, status dan kontribusi bawahannya. Production emphasis mengukur sejauh mana pemimpin menerapkan tekanan atau kekuasaan untuk mendapatkan hasil yang produktif. Predictive accuracy mengukur sejauh mana pemimpin menunjukkan pandangan ke depan dan kemampuan memprediksi hasil secara akurat. Integration mencerminkan sejauh mana pemimpin mempertahankan organisasi yang erat dan menyeleseaikan konfik antar anggota. Superior orientation sejauh mana pemimpin memelihara hubungan baik dengan atasan, memiliki pengaruh dengan mereka serta berjuang untuk status yang lebih tinggi.

Dari dimensi-dimensi perilaku kepemimpinan tersebut akan dikaitkan dengan kepuasan kerja karyawan/ bawahan, karena dari beberapa studi menyatakan bahwa perilaku kepemimpinan berpengaruh pada kepuasan kerja para bawahan mereka di tempat kerja. Cummings dkk. (2008) menemukan bahwa perawat kemungkinan akan tetap lebih berada dalam situasi kerja jika mereka memperoleh otonomi, kesempatan untuk berpartisipasi dalam kebijakan pengambilan keputusan, dukungan untuk inovasi, pengawasan dukungan dalam mengelola konflik, hubungan kerjasama atasan dan bawahan yang baik, kepemimpinan yang terlihat dan bawahan yang saling berkonsultasi dengan pimpinan. Di Afrika Selatan, secara khusus, Minnaar dan Selebi (2009) menemukan Perawat di Afrika tinggal di tempat kerja jika manajer/ atasan membuat mereka merasa nyaman dengan pekerjaan mereka. Sveinsdottir, Ragnarsdottir dan Blondal (2015) meneliti lebih lanjut dan menemukan bahwa perawat yang dipuji lebih sering menyatakan bahwa mereka memiliki lebih banyak kesempatan untuk berlatih secara profesional, lebih puas dengan pekerjaan mereka.

\section{B. Kepuasan kerja}

Kepuasan kerja (job satisfaction) sebagai suatu sikap umum seorang individu terhadap pekerjaannya. Seseorang dengan tingkat kepuasan kerja tinggi menunjukkan 
sikap yang positif terhadap kerja itu, seseorang yang tidak puas dengan pekerjaannya menunjukkan sikap yang negatif terhadap pekerjaan itu (Robbins, 2001). Menurut Blum dan Naylor (1986), kepuasan kerja adalah hasil dari beberapa sikap yang dimiliki oleh seorang pekerja terhadap pekerjaannya. Kepuasan kerja merupakan bidang penelitian yang memfokuskan antara dua pengaruh yaitu pengaruh pekerjaan organisasi terhadap pekerja dan pengaruh pekerja terhadap pekerjaan organisasi. Luthans (1998), menyatakan bahwa kepuasan kerja memiliki tiga dimensi. Pertama, kepuasan kerja adalah tanggapan emosional seseorang terhadap situasi kerjanya. Kepuasan ini bersifat abstrak, tidak dapat dilihat hanya dapat diduga. Kedua, kepuasan kerja hanya dapat ditentukan oleh sejauh mana hasil kerja memenuhi atau melebihi harapan seseorang. Jika mereka bekerja lebih berat dibandingkan orang lain pada organisasi yang sama, tetapi penghargaan yang diterima lebih rendah, maka mereka akan bersikap negatif terhadap pekerjaannya. Sebaliknya, jika mereka diperlakukan dengan baik, dan diberi penghargaan yang layak, maka mereka akan bersikap positif terhadap pekerjaannya. Ketiga, kepuasan kerja menunjukkan beberapa sikap seseorang yang saling terkait. Smith, Kendall, dan Hulin dalam Lok (1997) mengembangkan pengukuran kepuasan yang terdiri dari kepuasan terhadap pengawasan, hubungan pekerja, pekerjaan, penggajian, dan promosi. Pengukuran lain yang biasa digunakan yaitu dengan Job Diagnosic Index yang dikembangkan oleh Hackman dan Oldham (1975) yang mengukur kepuasan kerja dari lima dimensi pekerjaan yang terdiri dari skill variety, task identify, task significance, autonomy, dan job feedback.

yaitu:

Luthans (1998) menjelaskan faktor-faktor yang mempengaruhi kepuasan kerja,

1. Pekerjaan yang dilakukan. Jenis pekerjaan yang dilakukan dapat merupakan sumber kepuasan. Pekerjaan yang dapat memberikan kepuasan kerja adalah pekerjaan yang menarik dan menantang, tidak membosankan dan pekerjaan itu dapat memberikan status.

2. Gaji dan upah yang diterima karyawan dianggap sebagai refleksi cara pandang manajer mengenai kontribusi karyawan terhadap organisasi. Uang tidak hanya membantu orang untuk memenuhi kebutuhan dasarnya, tetapi juga dapat memberikan kepuasan pada tingkat berikutnya.

3. Promosi. Kesempatan untuk lebih berkembang di organisasi dapat menjadi sumber kepuasan kerja.

4. Supervisi. Kemampuan supervisor untuk memberikan bantuan teknis dan dukungan moral dapat meningkatkan kepuasan kerja. Sikap supervisor yang dapat meningkatkan kepuasan kerja adalah karyawan diberi kesempatan untuk berpartisipasi dalam pembuatan keputusan, supervisor yang memberi pengarahan dan bantuan pada karyawan, dan berkomunikasi dengan karyawan.

5. Lingkungan kerja dan rekan sekerja. Rekan kerja dapat memberikan bantuan secara teknis dan dapat mendukung secara sosial akan meningkatkan kepuasan kerja karyawan.

Luthans (1998) menjelaskan kepuasan kerja akan mempengaruhi faktor-faktor:

a. Produktivitas. Karyawan yang tingkat kepuasan kerjanya tinggi, produktivitasnya akan meningkat, walaupun hasilnya tidak langsung. Hasil penelitian sebelumnya menunjukkan bahwa ada beberapa variable moderating yang menghubungkan antara produktivitas dengan kepuasan kerja, terutama penghargaan. Jika karyawan menerima penghargaan yang mereka anggap layak, maka mereka akan merasa puas sehingga usaha untuk mencapai kinerja semakin tinggi.

b. Keinginan untuk berpindah (turnover). Jika karyawan tidak merasa puas terhadap pekerjaannya, maka besar keinginan mereka untuk pindah kerja. Walaupun demikian, hasil penelitian sebelumnya tidak mendukung pernyataan sebaliknya. Tingkat kepuasan kerja 
yang tinggi bukan berarti karyawan yang bekerja di organisasi tersebut tidak ingin pindah (turnover rendah).

c. Tingkat kehadiran. Hasil penelitian sebelumnya menunjukkan bahwa ketika tingkat kepuasan kerja tinggi maka tingkat ketidakhadiran (absen) rendah. Sebaliknya, ketika tingkat kepuasan rendah maka tingkat ketidakhadiran tinggi.

d. Faktor lain-lain. Penelitian sebelumnya menunjukkan bahwa karyawan yang tingkat kepuasannya tinggi akan mempunyai kesehatan fisik dan mental yang lebih baik, lebih cepat untuk mempelajari tugas-tugas, tidak banyak kesalahan yang dibuat, tidak banyak keluhan. Selain itu, karyawan akan menunjukkan perilaku dan aktivitas yang lebih baik, misalnya membantu rekan sejawat, membantu pelanggan, dan lebih mudah bekerja sama.

Terdapat banyak cara untuk mengukur kepuasan kerja karyawan dalam suatu organisasi/perusahaan besar maupun kecil. Menurut Luthans (1989) terdapat empat cara yang dapat dipakai untuk mengukur kepuasan kerja, yaitu: a). Rating scale, b). Critical Incidents, c). Interview, d). Action Tendencies.Studi tentang kepuasan kerja di dalam penelitian ini diukur dengan menggunakan kuesioner yang dikembangkan dalam instrumen Minnesota Satisfaction Questionnaire (MSQ). Pengukuran kepuasan kerja dilakukan ke dalam 20 item pertanyaan: ability utilization, achievement, activity, advancement, authority, company policies, compensation, co-workers, creativity, independence, moral values, recognition, responsibility, security, social status, social service, supervision - human relations, supervision - technical, variety, working conditions.

\section{Hipotesis}

Menurut Alimuddin, (2002), Thoha (2007), danNawawi (2008) bahwa suatu organisasi membutuhkan pemimpin yang efektif,yang mempunyai kemampuan mempengaruhi kinerja bawahannya untukmencapai tujuan organisasi. Adanya pengaruh antara kepemimpinan dengankepuasan kerja dibuktikan oleh (Andri, dkk. 2011), Bushra Fatima et al.(2011), Ghafoor et al.(2011) dalam penelitiannya yang membuktikan bahwakepemimpinan memiliki pengaruh kuat terhadap kepuasan kerja.

Lindblom dkk. (2016) melakukan penelitian pada industri ritel Finlandia yang berkaitan dengan pengaruh kepemimpinan karismatik pada kepuasan kerja, dan hasil penelitiannya menemukan bahwa kepemimpinan karismatik memiliki dampak yang kuat pada kepuasan kerja, yang berarti bahwa kepemimpinan karismatik berpengaruh terhadap kepuasan kerja. Penelitian ini juga berkaitan dengan Vlachos et al. (2013), yang juga melakukan penelitian pada kepemimpinan. Vlachos berpendapat bahwa pemimpin karismatik memaksakan perilaku yang memberi makna pada pekerjaan karyawan. Pemimpin ini juga memberikan tantangan dengan sasaran yang lebih luas. Setelah target tercapai, akan meningkatkan rasa kepuasan kerja bagi karyawan.

Berlatarbelakang kajian teori, hasil penelitian terdahulu dan fakta empiris makadilakukan penelitian hubungan antara variabel dimensi perilaku kepemimpinan terhadapkepuasan kerja. Penelitian ini mengajukan hipotesis yaitu: "Dimensi-dimensi Perilaku Kepemimpinan berpengaruh positif dan signifikan pada kepuasan kerja karyawan".

\section{METODE}

Dalam penelitian ini pengumpulan data dilakukan dengan menyebarkan kuesioner secara online kepada 60 praktisi bisnis di sektor perbankan Jawa Tengah. Kuesioner faktor LDBQ XII yang berisi 100 instrumen dikelompokkan ke dalam 12 faktor, serta didistribusikan dan diberi kode secara kualitatif untuk menghasilkan kombinasi perspektif bagaimana varian LDBQ XII dan kuesioner kepuasan kerja menggunakan Minnesota Satisfaction Questionnaire (MSQ) yang berisi 20 item untuk responden penelitian. 
HASIL DAN PEMBAHASAN

Tabel 1

Hasil Pengujian Analisis Regresi

\begin{tabular}{|c|c|c|c|c|c|c|c|c|}
\hline Independen & $\begin{array}{l}\text { Depe } \\
\text { nden }\end{array}$ & $\begin{array}{c}\text { Consta } \\
\text { nt }\end{array}$ & $B$ & $t$ & sig.t & Adj. $R^{2}$ & $\mathrm{~F}$ & Sig.F \\
\hline Representation & & 2,581 & 0,394 & 3,224 & 0,002 & 0,142 & 10,397 & 0,002 \\
\hline $\begin{array}{l}\text { Demand } \\
\text { Reconciliation }\end{array}$ & & 3,292 & 0,247 & 2,078 & 0,042 & 0,055 & 4,318 & 0,042 \\
\hline Tolerance & & 2,502 & 0,436 & 3,437 & 0,001 & 0,159 & 11,814 & 0,001 \\
\hline $\begin{array}{l}\text { Persuasivenes } \\
s\end{array}$ & & 1,605 & 0,627 & 6,096 & 0,000 & 0,388 & 37,159 & 0,000 \\
\hline & & 2,242 & 0,511 & 4,570 & 0,000 & 0,259 & 20,888 & 0,000 \\
\hline & Satis & 2,197 & 0,526 & 6,559 & 0,000 & 0,424 & 43,017 & 0,000 \\
\hline $\begin{array}{l}\text { Role } \\
\text { Assumption }\end{array}$ & $\begin{array}{l}\text { factio } \\
n\end{array}$ & 2,611 & 0,423 & 4,745 & 0,000 & 0,274 & 22,510 & 0,000 \\
\hline Consideration & & 2,917 & 0,340 & 3,850 & 0,000 & 0,195 & 14,825 & 0,000 \\
\hline $\begin{array}{l}\text { Production } \\
\text { Emphasizes }\end{array}$ & & 1,583 & 0,615 & 7,696 & 0,000 & 0,505 & 59,222 & 0,000 \\
\hline $\begin{array}{l}\text { Predictive } \\
\text { Accuracy }\end{array}$ & & 1,770 & 0,569 & 6,536 & 0,000 & 0,423 & 42,725 & 0,000 \\
\hline Integration & & 2,522 & 0,409 & 4,594 & 0,000 & 0,261 & 21,108 & 0,000 \\
\hline $\begin{array}{l}\text { Superior } \\
\text { Orientation }\end{array}$ & & 2,626 & 0,391 & 4,041 & 0,000 & 0,212 & 16,328 & 0,000 \\
\hline
\end{tabular}

Tabel 1 menunjukkan hasil bahwa 12 faktor/ dimensi kepemimpinan berpengaruh positif pada kepuasan kerja. Dari nilai signifikansi menunjukkan bahwa semua dimensi kepemimpinan adalah signifikan pada kepuasan kerja. Hasil ini sejalan dengan hasil penelitian yang dilakukan oleh Cakmak et al., (2015). Hasil penelitian dengan dimensi 12 deskripsi perilaku kepemimpinan ini valid dan reliabel (Soderholm,et al., 2019). Dari sebanyak 12 faktor tersebut, faktor yang memiliki pengaruh paling besar adalah persuasiveness dengan nilai beta sebesar 0,627. Secara berturut-turut factor kepemimpinan yang berpengaruh positif pada kepuasan kerja adalah: Persuasiveness, Production Emphasizes, Predictive Accuracy, Tolerance of Freedom, dan Initiation for Structure. Dapat disampaikan bahwa factor yang paling berpengaruh pada kepuasan kerja manajer/supervisor/praktisi perbankan di Jawa Tengah dari 12 dimensi deskripsi perilaku kepemimpinan adalah 1). Persuasiveness: mengukur sejauh mana pemimpin menggunakan persuasi dan argumen secara efektif untuk menunjukkan keyakinan yang kuat; Diharapkan, dengan adanya pemimpin yang bisa menggunakan argumen yang dimiliki serta menunjukkan keyakinan yang kuat pada anggotanya, maka semakin bisa diterima pendapatnya dan semakin meningkatkan kepuasan kerja anggotanya. 2). Production Emphasizes: mengukur sejauh mana pemimpin menerapkan tekanan atau kekuasaan untuk mendapatkan hasil yang produktif; Dengan dimilikinya sumber kekuasaannya yang dapat dimanfaatkan dengan baik serta diperoleh hasil yang produktif, maka akan semakin meningkatkan kepuasan bawahan/ anggotanya. 3). Predictive Accuracy: mengukur sejauh mana pemimpin menunjukkan pandangan ke depan dan kemampuan memprediksi hasil secara akurat; Dengan kemampuan pemimpin yang dapat menunjukkan kemampuannya di dalam memprediksi hasil secara akurat kepada 
anggotanya, maka akan semakin meningkatkan kepuasan para bawahan di tempat kerjanya. 4). Tolerance of Freedommencerminkan sejauh mana pemimpin memungkinkan ruang lingkup bagi bawahan untuk mengambil inisiatif, keputusan, dan tindakan. Dengan adanya sikap pemimpin yang memberikan kesempatan kepada bawahan untuk mengambil inisiatif, keputusan dan tindakan bawahannya, maka semakin meningkatkan kepuasan bawahannya, dan 5). Initiation for Structure: mengukur sejauh mana pemimpin secara jelas mendefinisikan peran mereka sendiri dan membiarkan pengikut mengetahui apa yang diharapkannya.

Dengan sikap yang ditunjukkan tersebut, maka bawahan akan mengetahui peran yang dilakukan oleh pemimpin dan memberikan kesempatan bawahan untuk mengetahui peran tersebut, maka akan semakin meningkatkan kepuasan bawahannya.

\section{SIMPULAN}

Hasil penelitian menunjukkan bahwa masyarakat Indonesia, khususnya di wilayah Jawa Tengah lebih memilih pemimpin yang bisa menggunakan argumen yang dimilikinya serta menunjukkan keyakinan yang kuat pada anggotanya, dan dimilikinya sumber kekuasaan yang dapat dimanfaatkan dengan baik serta diperoleh hasil yang produktif, demikian pula pemimpin yang dapat menunjukkan kemampuannya di dalam memprediksi hasil secara akurat kepada anggotanya, serta adanya sikap pemimpin yang memberikan kesempatan kepada bawahan untuk mengambil inisiatif, keputusan dan tindakan bawahannya, dan bawahan akan mengetahui peran yang dilakukan oleh pemimpin dan yang memberikan kesempatan bawahan untuk mengetahui peran tersebut. Semua dimensi/ factor kepemimpinan tersebut secara berturut-turut akan meningkatkan kepuasan bawahan/ manajer dan supervisor praktisi perbankan di Jawa Tengah. Keterbatasan dari penelitian adalah bahwa studi ini merupakan bagian dari keseluruhan penelitian tentang masalah tersebut dan merupakan studi pendahuluan dari keseluruhan penelitian.

\section{DAFTAR PUSTAKA}

Abraham, J., \& Grant, L. A. (2008). Leadership competencies and employee satisfactioninnursing homes. Seniors Housing \& Care Journal, 16 (1), 11-23

Andri, Seno, Eka Afnan Troena, Idrus, dan Djumahir. (2011). Pengaruh Gaya Kepemimpinan, Budaya Organisasi, Motivasi, Program Diklat terhadap Kinerja dan Kepuasan Kerja Karyawan pada PT. Telkom Tbk Pekanbaru. Jurnal Aplikasi Manajemen, Vol. 9 No. (4), Juli 2011. Hal 1.

Barnes, L. L. (2011). Job satisfaction and organizational commitment: An empirical investigationof the effects of servant leadership in distance education programs. Order No. 3465555, Capella University.

Bathini, V. S. (1996). Relationship between leadership practices of Seventh-day Adventist administrators and teacher job satisfaction of Seventh-day Adventist teachers in India. Order No. 9704964, La Sierra University.

Burns, J. D. (2007). Analyses of transactional and transformational leadership on job satisfactionof college faculty. Order No. 3294383, Northcentral University

Bushra Fatima, Usman Ahmad, Naveed Asvir, (2011). Effect of Transformational Leadership on Employees' Job Satisfaction and OrganizationalCommitment in Banking Sector of Lahore (Pakistan). International Journal of Business and Social Science Vol. 2 No. (18), October 2011.pp.261.

Caffey, R. D. (2012). The relationship between servant leadership of principals and beginning teacherjob satisfaction and intent to stay. Order No. 3530849, University of Missouri-Columbia. 
Cakmak, Oztekin, Karadag. (2015). The Effect of Leadership on Job Satisfaction. Springer International Publishing Switzerland 2015. Leadership and Organizational Outcomes, DOI 10.1007/978-3-319-14908-0_3

Chen, H. (2005). The influence of nursing directors' leadership styles on Taiwanese nursing faculty job satisfaction. Order No. 3172100, University of South Dakota.

. Exploring the relationship among transformational and transactional leadershipbehavior, job satisfaction, organizational commitment, and turnover on the IT department ofresearch and development in shanghai, china. Order No. 3169070, Nova Southeastern University.

Cummings, G.G., Olson, K., Hayduk, L., Bakker, D., Fitch, M., Green, E. et al., 2008, 'Therelationship between nursing leadership and nurses' job satisfaction in Canadianoncology work environment', Journal of Nursing Management, 16 (1), 508-518.http://dx.doi.org/10.1111/j.1365-2834.2008.00897

Darvish, H., \& Rezaei, F. (2011). The impact of authentic leadership on job satisfaction and teamcommitment. Management \& Marketing, 6 (3), 421-436.

Derzsy, M. (2003). The relationship between leadership styles of sales managers and employee jobsatisfaction: An empirical examination. Order No. 3117407, Capella University.

Drury, S. (2004). Employee perceptions of servant leadership: Comparisons by level and with jobsatisfaction and organizational commitment. Order No. 3146724, Regent University.

Einstein, J. E. (2013). Ethical leadership and service climate: The relationship with job satisfaction and organizational identification. Order No. 3561141, Nova Southeastern University.

Gharibvand, S. (2012). The relationship between Malaysian organizational culture, participativeleadership style, and employee job satisfaction among Malaysian employees from semiconductor industry. International Journal of Business and Social Science, 3 (16), 289-298.

Ghafoor MM, Malik ME, Naseer S, (2011). Transformational leadership, employeeengagementand performance: Mediating effect of psychology calownership. African Journal of Business Management Vol. 5 (17), pp. 73917403, 4 September, 2011.

Giallonardo, L. M., Wong, C. A., \& Iwasiw, C. L. (2010). Authentic leadership of preceptors: Predictor of new graduate nurses' work engagement and job satisfaction. Journal of Nursing Management, 18 (8), 993-1003.

Hackman, J. R., \& Oldham, G. R. (1975). Development of the Job Diagnostic Survey. Journal of Applied Psychology, 60, $159-170$.

Hebert, S. C. (2003). The relationship of perceived servant leadership and job satisfaction from thefollower's perspective. Order No. 3112981, Capella University.

Hemphill, J.K. and Coons, A.E. (1957). Development of the Leader behavior Description Questionnaire. In R.M. Stogdill, and A.E. Coons (Eds.), Leader Behavior: Its Description and Measurement. Columbus: The Ohio State University, Bureau of Business Research, Monograph No. 88, 1957

Henson, P. R. (1984). The relationship between perceived superintendent leadership adaptability,principal role-based stress, and job satisfaction. Order No. 8504212, Washington StateUniversity.

Holloway, K. (2012). An examination of the relationship between charismatic leadership and jobsatisfaction. Order No. 3542615, Capella University.

Ivie, S. C. (2007). School leaders' behavior informed by thirteen core leadership competencies and the relationship to teacher job satisfaction. Order No. 3263702, The University of Memphis. 
Kim, S. (2002). Participative management and job satisfaction: Lessons for management leadership. Public Administration Review, 62 (2), 231-241.

Konto, E. J. K. (1986). The relationship of vocational and technical instructors' job satisfaction and their perception of the area vocational technical school director's leadership style in vocational technical schools in the state of Missouri. Order No. 8701385, University of Missouri-Columbia.

Lin, C. H. (1998). Perceived presidential leadership styles and faculty job satisfaction at Taiwanese institutes of technology. Order No. 3114016, University of South Dakota.

Lindblom, A., Kajalo, S., \& Mitronen, L. (2016). Does a Retailer's Charisma Matter? A Study of Frontline Employee Perceptions of Charisma in the Retail Setting. Journal of Services Marketing, 3, 266-276.

Lowhorn, G. L. (2009). The effect of supportive organizational leadership, organizational socialization, and satisfaction with supervision on turnover as mediated by organizational commitment and job satisfaction in faculty. Order No. 3377768, Regent University.

Luthans, F. (1989). Organisational behaviour (5th ed.). New York, NY: Mc Graw-Hill.

Marra, P. R. (1978). Principal's leadership behavior, teacher's decisional participation, teacher'sjob satisfaction and student achievement. Order No. 7816572, Fordham University.

McElhaney, R. F. (2003). Perceptions of nurse managers' leadership style by nurse managers andRN staff: Job satisfaction as perceived by RN staff. Order No. 3093847, Louisiana StateUniversity Health Sciences Center School of Nursing.

Miears, L. D. (2004). Servant-leadership and job satisfaction: A correlational study in Texas education agency region $X$ public schools. Order No. 3148083, Texas A\&M University-Commerce.

Miller, G. G. (2003). Leadership behavior of east Tennessee directors of public schools and the jobsatisfaction of principals. Order No. 3119290, The University of Tennessee.

Minnaar, A. \& Selebi, C. (2009). 'Our greatest loss: Why are nurses in South Africaleaving their jobs? Where to focus to keep the nurses', Curationis, 33 (6), 29-35.

Nawawi, Hadari. (2008). Perencanaan SDM untuk Organisasi Profit yang Kompetitif. Yogyakarta: UGM Press.

Nongmak, C. (1986). The relation between teacher job satisfaction and the leadership behavior ofprimary school principals in Thailand. Order No. 8716714, University of Missouri-Columbia.

Northouse, P. G. (2013). Leadership: Theory and practice. Thousand Oaks. CA: SAGE Publications.

Oberlin, M. H. (1980). Effects of leadership on perceived job satisfaction and influence among intermediate school district special education personnel in Michigan. Order No. 8020726, Michigan State University.

Prest, G. S. (1993). A study of instructional assistants' job satisfaction and supervising teachers'leadership behavior. Order No. 9328319, University of Minnesota.

Robbins, S. (2001). Organizational behaviour (9h ed.). Upper Saddle River. NY: Prentice Hall.

Roelle, R. J. (2010). Better school superintendents, more effective principals? A study of the relationship between superintendent leadership practices and principal job satisfaction. Order No. 3407464, Fordham University.

Rothfelder, K., Ottenbacher, M. C., \& Harrington, R. J. (2013). The impact of transformational, transactional and non-leadership styles on employee job satisfaction in the German hospitalityindustry. Tourism and Hospitality Research, 12 (4), 201-214. 
Ruiz-Palomino, P., Sa'ez-Martı 'nez, F. J., \& Martı 'nez-Cañas, R. (2013). Understanding pay satisfaction: Effects of supervisor ethical leadership on job motivating potential influence. Journal of Business Ethics, 118 (1), 31-43.

Schulman, J. M. (1989). Power behavior, job satisfaction and leadership effectiveness in public school principals. Order No. 8921859, University of Bridgeport.

Shibru, B., \& Darshan, G. M. (2011). Effects of transformational leadership on subordinate job satisfaction in leather companies in Ethiopia. International Journal of Business Management \& Economic Research, 3 (5), 284-296.

Smith, J. P. II. (2011). The effects of self-efficacy and spirituality on the job satisfaction and motivation to lead among redeploying soldiers as moderated by transformational leadership. Order No. 3447893, Regent University.

Soderholm, Minergaite, Littrell. (2019). From LBDQ XII to LBDQ50: preferred leader behavior measurement across cultures. National Research University Higher School of Economic, Moscow, Rusia, \& Centre for Cross Cultural Comparisons, Miami, Florida, USA.

Stearns, M. (2012). The relationship of leadership behaviors to staff RN job satisfaction and retention. Order No. 3523913, Grand Canyon University.

Stogdill, R. M., Goode, O. S., and Day, D. R. 1963. The leader behavior of corporation presidents. Personnel Psychol, 16, 127-132

Sveinsdottir, H, Ragnarsdottir, E.D. \& Blondal, K., (2015), 'Praise matters: The influence of nurse unit managers' praise on nurses' practice, work environment and jobsatisfaction: A questionnaire study', Journal of Advanced Nursing 72 (3), 558-568.http://dx.doi.org/10.1111/jan. 12849

Taylor, C. D. (1996). An investigation of the relationships between perceived leadership behaviors, and staff nurse job satisfaction, and organizational commitment. Order No. 1381005, Bellarmine College.

Thoha, Miftah. (2007). Kinerja Organisasi: Konsep Dasar dan Aplikasinya. Jakarta: Rajawali Pers

Thompson, M. K. (2005). Involvement in instructional leadership and job satisfaction among assistant principals. Order No. 3188217, University of Wyoming.

Tomsheck, L. E. (1985). The impact of self-persuasion communication, leadership, involvement, and role differences on commitment and job performance in volunteer extension advisorycouncils: $A$ path and experimental analysis (satisfaction, reward, role ambiguity, feedback, meeting attendance). Order No. 8529548, University of Oregon.

Undang-undang Nomor 10 Tahun (1998). Perubahan Atas Undang-Undang Nomor 7 Tahun 1992 Tentang Perbankan

Vlachos, P. A., Panagopoulos, N. G., \& Rapp, A. A. (2013). Feeling good by doing good: Employee CSR-induced attributions, job satisfaction, and the role of charismatic leadership. Journal of Business Ethics, 118 (3), 577-588.

Walumbwa, O. F. (2002). The relationships between leadership styles, cultural orientation, organizational commitment, job satisfaction and perceptions of organizational withdrawalbehaviors. Order No. 3044253, University of Illinois at Urbana-Champaign.

Westley, E. E. (2000). An examination of the relationships between catholic grade school teachers' perceptions of job satisfaction and their expectations of leadership effectiveness. Order No. 9992285, Wayne State University.

Wilson, D. F. (2013). Servant leadership and job satisfaction in a multicultural hospitality organization: A quantitative, non-experimental descriptive study. Order No. 3597448, Grand Canyon University. 